\title{
Yersinia pseudotuberculosis and Yersinia pestis are more resistant to bactericidal cationic peptides than Yersinia enterocolitica
}

\author{
José-Antonio Bengoechea, ${ }^{1,2}$ Buko Lindner, ${ }^{2}$ Ulrich Seydel, ${ }^{2}$ Ramón Díaz ${ }^{1}$ \\ and Ignacio Moriyón ${ }^{1}$
}

1 Departamento de Microbiología, Universidad de Navarra, Aptdo. 177, 31080 Pamplona, Spain

2 Forschungzentrum Borstel, Division of Biophysics, Borstel, Germany
Author for correspondence: Ignacio Moriyón. Tel: +34 48 425600. Fax: + 3448425649. e-mail: imoriyon@unav.es

The action of bactericidal polycationic peptides was compared in Yersinia spp. by testing peptide binding to live cells and changes in outer membrane (OM) morphology and permeability. Moreover, polycation interaction with LPS was studied by measuring the dependence of dansylcadaverine displacement and zeta potential on polycation concentration. When grown at $37^{\circ} \mathrm{C}$, Yersinia pestis and Yersinia pseudotuberculosis bound less polymyxin B (PMB) than pathogenic or non-pathogenic Yersinia enterocolitica, regardless of virulence plasmid expression. Y. pseudotuberculosis OMs were unharmed by PMB concentrations causing extensive $O M$ blebbing in $Y$. enterocolitica. The permeability to lysozyme caused by PMB was greater in $Y$. enterocolitica than in Y. pseudotuberculosis or $Y$. pestis and differences increased at $37^{\circ} \mathrm{C}$. Similar observations were made with other polycations using a polymyxin/novobiocin permeability assay. With LPS of cells grown at $26{ }^{\circ} \mathrm{C}$, polycation binding was highest for $Y$. pseudotuberculosis and lowest for $Y$. pestis, with $Y$.

enterocolitica yielding intermediate results which were lower for pathogenic than for non-pathogenic strains. With LPS of cells grown at $37{ }^{\circ} \mathrm{C}$, polycation binding remained unchanged for $Y$. pestis and pathogenic $Y$. enterocolitica, increased for non-pathogenic $Y$. enterocolitica and decreased for $Y$. pseudotuberculosis to $Y$. pestis levels. Polycation binding related in part to differences in charge density (zeta potential) of LPS aggregates, suggesting similar effects at bacterial surfaces. It is suggested that species and temperature differences in polycation resistance relate to infection route, invasiveness and intracellular multiplication of Yersinia spp.

Keywords: Yersinia, polycations, lipopolysaccharide

\section{INTRODUCTION}

The yersiniae are Gram-negative bacteria distributed into several species which show wide differences in pathogenicity and invasiveness. Yersinia enterocolitica includes both non-pathogenic and pathogenic biogroups, and Yersinia pseudotuberculosis and Yersinia pestis are characteristically pathogenic (Brubaker, 1991; Straley \& Perry, 1995). In humans, pathogenic Y. enterocolitica and Y.pseudotuberculosis cause intestinal infections but the latter is more invasive (Brubaker,

Abbreviations: $D C$, dansylcadaverine; Kdo, 3-deoxy-D-manno-2octulosonic acid; OM, outer membrane; $\mathrm{PMB}$, polymyxin $\mathrm{B}$; $\mathrm{PMBN}$, deacylated nonapeptide derivative of polymyxin $B$.
1991). In contrast, Y. pestis enters the body by nonenteric routes and it is characteristically able to multiply intracellularly (Brubaker, 1991; Straley \& Harmon, 1984a, b). Pathogenic yersiniae carry a virulence plasmid (pYV) and many virulence-related properties regulated at plasmid and chromosome levels are manifested only under certain conditions such as growth at $37^{\circ} \mathrm{C}$ and divalent cation restriction (Brubaker, 1991; Cornelis et al., 1995; Straley \& Perry, 1995).

It has been shown that, independently from pYV, pathogenic $Y$. enterocolitica is more resistant to polycations than non-pathogenic Y. enterocolitica or enteropathogenic Escherichia coli (Bengoechea et al., 1996). This could reflect an adaptation to environments where bactericidal peptides act (Eisenhauer et al., 1992; 
Groissman, 1994; Selsted et al., 1992) and, if so, the hypothesis can be formulated that the more invasive yersiniae should have an increased resistance. We report here that live cells of Y.pseudotuberculosis and Y.pestis are more resistant to polycations than those of pathogenic $Y$. enterocolitica. Moreover, since LPS is a main polycation target (Vaara, 1992) and an assessment of its role necessarily precedes and could make chemical characterization relevant (Helander et al., 1994, 1996; Nummila et al., 1995; Sidorczyk et al., 1983), we have analysed LPS-polycation affinity and the effects at supramolecular (i.e. aggregate) level.

\section{METHODS}

Bacterial strains and growth conditions. The strains used were $Y$. enterocolitica PR serotype O:1,6 (non-pathogenic) and WE 245/92 serotype O:3 (pathogenic), Y. enterocolitica WA 289 serotype O:8 (pathogenic), Y. pseudotuberculosis WE 23/90 serogroup I, WS 41/91 serogroup I, WS 45/91 serogroup II and WS 66/89 serogroup III, and Y. pestis KIM. All pathogenic strains and species, except $Y$. pestis KIM, carried $\mathrm{pYV}$, as shown by detection of the YadA protein by autoagglutination (Skurnik \& Toivanen, 1992). Selection of $\mathrm{pYV}^{+}$and plasmid-cured $\mathrm{pYV}^{-}$isogenic pairs was performed on Congo Red/magnesium/oxalate medium (Riley \& Toma, 1989). These pairs were stored in skimmed milk at $-80^{\circ} \mathrm{C}$ and, where appropriate, inocula were taken directly from these frozen seeds to minimize $\mathrm{pYV}^{+/-}$dissociation. For polycation binding and sensitivity studies, bacteria were grown in sidearm flasks containing tryptic soy broth or, for pYV expression, magnesium/oxalate broth (Riley \& Toma, 1989) on an orbital shaker at 26 or $37^{\circ} \mathrm{C}$. Growth was monitored by measuring $\mathrm{OD}_{540}$ and exponentially growing cells were harvested $\left(5000 \mathrm{~g}, 20 \mathrm{~min}, 5^{\circ} \mathrm{C}\right)$, resuspended in the appropriate buffer (see below) and tested immediately. For LPS extraction, Y. enterocolitica and Y. pseudotuberculosis were grown in tryptic soy broth and Y. pestis in brain-heart infusion at 26 and $37^{\circ} \mathrm{C}$.

Polymyxin B (PMB) binding by viable cells. Bacteria $\left(1.25 \times 10^{10}\right.$ c.f.u. $\left.\mathrm{ml}^{-1}\right)$ were incubated with PMB $(12.5 \mu \mathrm{g}$ $\mathrm{ml}^{-1}$ ) in $2 \mathrm{mM}$ HEPES ( $\mathrm{pH} \mathrm{7.5)}$ for $5 \mathrm{~min}$ at the growth temperature and sedimented $(12000 \mathrm{~g}, 10 \mathrm{~min})$. Unbound PMB was measured in the supernatants. For this, Petri dishes (10 cm diam.) were layered with $12 \mathrm{ml}$ of a solution containing
$0 \cdot 1 \%$ glucose, $0 \cdot 1 \%$ peptone, $0.05 \%$ yeast extract, $1 \%$ agarose [type II-A (medium electroendosmosis); Sigma] previously inoculated with $6 \cdot 1 \times 10^{5}$ c.f.u. E. coli K-12 $\mathrm{ml}^{-1}$, and wells $(5 \mathrm{~mm}$ diam.) were punched and filled with $30 \mu \mathrm{l}$ of the supernatants. After overnight incubation in a wet chamber at $37^{\circ} \mathrm{C}$, inhibition haloes were measured and the amount of antibiotic calculated using PMB dilutions tested on the same plate. Direct binding was assessed by taking advantage of the fact that the fluorescent group of dansylated PMB increases its quantum yield when the peptide moiety becomes attached to a target. Fresh cells at an $\mathrm{OD}_{600}$ of 0.5 in $1 \mathrm{mM} \mathrm{KCN} / 2 \mathrm{mM}$ HEPES ( $\mathrm{pH} 7 \cdot 2$ ) were supplemented with dansyl-PMB $(3.8 \mu \mathrm{M}$ final concentration) (Schindler \& Tauber, 1975). The fluorescence was measured at the growth temperature in $1 \mathrm{~cm}$ diameter cuvettes with a LS-50 fluorimeter (Perkin-Elmer; excitation $340 \mathrm{~nm}$, emission $485 \mathrm{~nm}$, slit width $4.0 \mathrm{~nm}$ ) and results were expressed in relative fluorescence units (RFU). All the above measurements were performed twice with each of two independently grown batches of cells.

Assessment of OM damage. Cells $\left(10^{10}\right.$ c.f.u. $\left.\mathrm{ml}^{-1}\right)$ were incubated with PMB $\left(10 \mu \mathrm{g} \mathrm{ml}^{-1}\right)$ in $2 \mathrm{mM}$ HEPES ( $\left.\mathrm{pH} 7 \cdot 1\right)$ for $20 \mathrm{~min}$ at the growth temperature, sedimented $(12000 \mathrm{~g}$, $5 \mathrm{~min}$ ), fixed with glutaraldehyde/cacodylate and $\mathrm{OsO}_{4} /$ cacodylate and embedded in agarose. Thin sections were examined by electron microscopy (Martínez de Tejada $e t$ al., 1995).

Changes in OM permeability were tested using lysozyme and novobiocin as hydrophilic and hydrophobic probes, respectively. Cell suspensions $\left(\mathrm{OD}_{500}\right.$ of 0.8$)$ were incubated with lysozyme $\left(50 \mu \mathrm{g} \mathrm{ml}^{-1}\right)$ and PMB $\left(12.5 \mu \mathrm{g} \mathrm{m}^{-1}\right)$ in $2 \mathrm{mM}$ HEPES $(\mathrm{pH} 7 \cdot 1)$ and lysis was assessed as the decrease in $\mathrm{OD}_{500}$ after $1 \mathrm{~h}$ (time at which lysis was maximal for sensitive strains) at the growth temperature. Lysozyme or PMB alone did not produce any decrease in OD under these conditions. For novobiocin, antibiotic dilutions were made in Mueller-Hinton broth in 96-well polystyrene plates which were then inoculated with $1.25 \times 10^{6}$ exponentially growing c.f.u. $\left(37^{\circ} \mathrm{C}\right)$ in $100 \mu \mathrm{l}$ broth containing appropriate amounts of polycations (Table 1) (Vaara \& Vaara, 1983). After incubation at $37^{\circ} \mathrm{C}$ for $18 \mathrm{~h}$, the lowest novobiocin concentration that inhibited growth was taken as the MIC. Polycations by themselves had no inhibitory effect under those conditions. All measurements were performed two times with each of two independently grown batches of cells.

LPS preparations. The LPSs of Y. enterocolitica PR O:16 (non-pathogenic), WA 289 O:8 (pathogenic) and WE 245/92

Table 1. Effect of subinhibitory concentrations of polycations on the permeability of Yersinia spp. to novobiocin

\begin{tabular}{|c|c|c|c|c|c|}
\hline \multirow[t]{3}{*}{ Strain } & \multicolumn{5}{|c|}{ Novobiocin MIC $\left(\mu \mathrm{g} \mathrm{ml}^{-1}\right)$} \\
\hline & \multirow[b]{2}{*}{$\begin{array}{c}\text { No } \\
\text { polycation }\end{array}$} & \multicolumn{4}{|c|}{ Polycation ( $\mu \mathrm{g} \mathrm{ml}^{-1}$ ) } \\
\hline & & $\begin{array}{l}\text { PMB } \\
(0.01)\end{array}$ & $\begin{array}{l}\text { Poly-L-lysine } \\
\text { (25) }\end{array}$ & $\begin{array}{c}\text { Poly-L-ornithine } \\
\qquad(25)\end{array}$ & $\begin{array}{l}\text { Melittin } \\
\text { (2) }\end{array}$ \\
\hline Y. enterocolitica WA $2890: 8$ & 256 & 32 & 16 & 4 & 32 \\
\hline Y. pestis KIM & 32 & 32 & 32 & 32 & 32 \\
\hline Y. pseudotuberculosis WE 23/90 & 16 & 8 & 16 & 16 & 16 \\
\hline Y. pseudotuberculosis WS 41/91 & 32 & 16 & 32 & 32 & 32 \\
\hline Y.pseudotuberculosis WS 45/91 & 32 & 32 & 32 & 32 & 16 \\
\hline Y. pseudotuberculosis WS 66/89 & 64 & 16 & 64 & 64 & 64 \\
\hline
\end{tabular}


O:3 (pathogenic), Y. pseudotuberculosis WE 23/90 and Y. pestis KIM were extracted, purified, characterized as described in the accompanying article [Bengoechea et al., 1998; protein, phospholipid and 3-deoxy-D-manno-2-octulosonic acid (Kdo) contents, and SDS-PAGE] and used as the natural salt forms.

Affinity of polycations for LPS molecules. LPS-polycation affinity was assessed using dansylcadaverine (DC) as probe and estimated as the amount of PMB (in $\mathrm{nM}$ ) displacing $50 \%$ of the DC bound by a given LPS (David et al., 1992). To obtain DC-LPS complexes, LPS stocks $\left(3 \mathrm{mg} \mathrm{ml}^{-1}\right)$ were diluted in $1.5 \mathrm{ml} 2 \mathrm{mM}$ HEPES ( $\mathrm{pH} 7.5$ ) in fluorimetric cuvettes at a concentration equivalent to $4 \mathrm{nmol} \mathrm{Kdo} \mathrm{ml}^{-1}$ and $12 \mathrm{nmol} \mathrm{DC}$ was added. This DC concentration yielded $90 \%$ of the maximal fluorescence possible and did not produce detectable inner-filter effects. Fluorescence was recorded with a SPEX F1T11 apparatus (excitation $340 \mathrm{~nm}$, emission scan from 400 to $600 \mathrm{~nm}$, slit width for both windows $1.5 \mathrm{~nm}$ ) and the DC occupancies were calculated as $\left(F-F_{0}\right) /\left(F_{\max }-F_{0}\right)$ where fluorescence values are that of DC alone $\left(F_{0}\right)$, DC-LPS $\left(F_{\max }\right)$ and DC-LPS/PMB mixtures $(F)$. The $50 \%$ occupancy was calculated from occupancy versus PMB concentration plots. For each LPS, all experiments were performed twice with two different LPS suspensions. PMB did not produce any decrease in the fluorescence intensity of free DC.

Effect of polycations on zeta potentials of LPS aggregates. The surface charge density of LPS aggregates and the effect of polycations was measured as the electrophoretically effective potential (zeta potential or $\zeta_{\mathrm{sm}}$ ) of the aggregates (Cafiso et al., 1983) with varying concentrations of PMB or its deacylated nonapeptide (PMBN). Particle size and $\zeta_{\mathrm{sm}}$ were measured in a ZetaSizer 4 apparatus (Malvern Instruments) using a $5 \mathrm{~mW}$ $\mathrm{He} / \mathrm{Ne}$ laser and a temperature-controlled electrophoresis cell to measure the electrophoretic mobility by laser Doppler anemometry and the size distribution by photon correlation spectroscopy at a scatter angle of $90^{\circ}$. The cell was frequently checked for instrumental drifts and, if necessary, cleaned and recalibrated. The electrokinetic mobility $\left(\mu_{\mathrm{cl}}\right)$ of the aggregates was measured at $22{ }^{\circ} \mathrm{C}$ in a driving electric field of $19 \cdot 2 \mathrm{~V} \mathrm{~cm}^{-1}$ from which, independent of the particle size, $\zeta_{s m}$ can be calculated according to the Helmholtz-Smoluchowsky equation, $\zeta_{\mathrm{sm}}=\left(\mu_{\mathrm{cl}} \times \eta\right) /\left(\varepsilon_{\mathrm{r}} \times \varepsilon_{0}\right)$, where $\mu_{\mathrm{c} 1}$ is the electrokinetic mobility, $\eta$ is the viscosity $(0.97 \mathrm{mPa}), \varepsilon_{\mathrm{r}}$ is the dielectric constant of the buffer (79) and $\varepsilon_{0}$ is the permittivity of free space (Hunter, 1981). LPS aggregates were prepared in $1 \mathrm{mM}$ $\mathrm{CsCl} / 2.5 \mathrm{mM}$ Tris $/ \mathrm{HCl}(\mathrm{pH} 7.0)$ by sonication for $20 \mathrm{~min}$ at $40^{\circ} \mathrm{C}$ in an ultrasonic bath (Sonorex RK100, Bandelin Electronics) and allowed to equilibrate at $4{ }^{\circ} \mathrm{C}$ overnight before measurements. The aggregates thus formed had similar broad size distributions with mean diameters between 65 and $118 \mathrm{~nm}$. The suspensions were adjusted to the same Kdo concentration, approximately $40 \cdot 5 \mu \mathrm{M}$, and for each LPS two different suspensions were examined, with six independent measurements for each PMB or PMBN concentration.

Chemicals. PMB (8000 units $\mathrm{mg}^{-\mathbf{1}}$ ) and PMBN, poly-L-lysine (molecular mass 7000-10000 Da), poly-L-ornithine (1200022000), melittin, lysozyme, novobiocin, dansylcadaverine and dansyl chloride were all purchased from Sigma.

\section{RESULTS}

\section{Action of polycations on Yersinia spp.}

As shown in Fig. 1(a), the amount of PMB absorbed by bacteria grown at $37^{\circ} \mathrm{C}$ progressively decreased in the order non-pathogenic $Y$. enterocolitica PR $O: 1,6-$ pathogenic Y. enterocolitica WA 289 O:8-Y. pseudo-
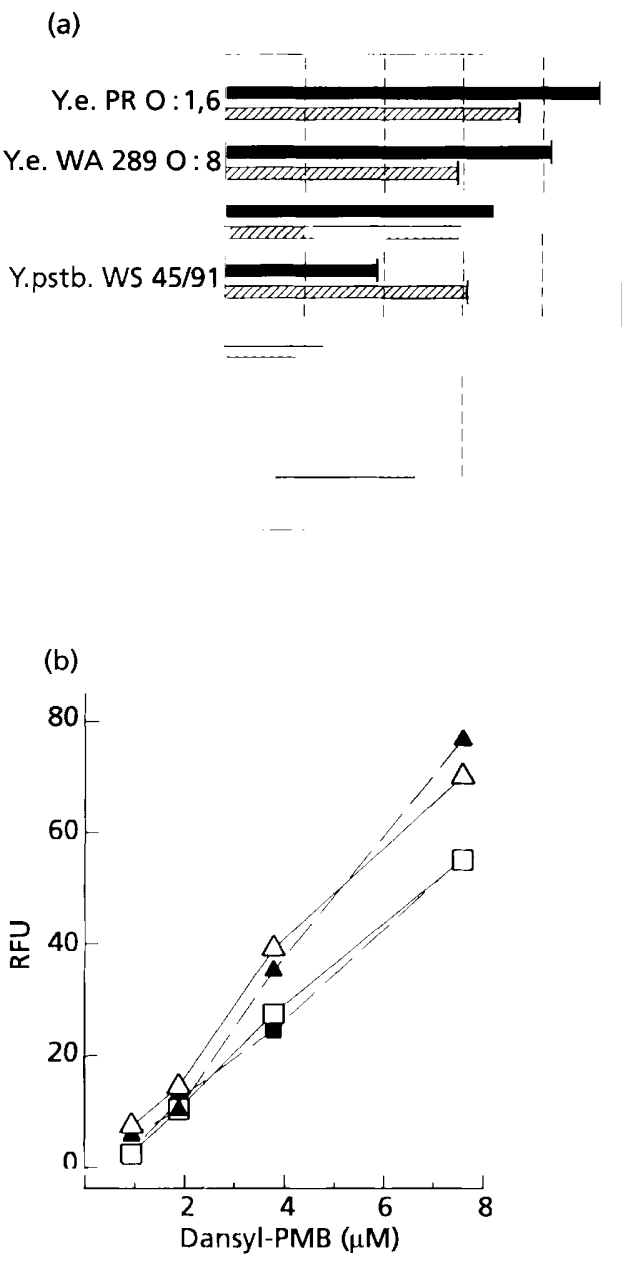

Fig. 1. $P M B$ binding to Yersinia spp. live cells and influence of pYV. (a) Amounts of PMB absorbed by $Y$. enterocolitica (Y.e.), Y. pseudotuberculosis (Y.pstb.) and Y. pestis (Y.p.) grown at 26 $(\nabla)$ or $37^{\circ} \mathrm{C}(\boldsymbol{\square})$. (b) Dansyl-PMB binding to $Y$. enterocolitica WA 289 0:8 ( $\triangle . \mathbf{A})$ and $Y$. pseudotuberculosis WE 23/90 $(\square, \boldsymbol{\square})$ live cells lacking $(\boldsymbol{\Lambda}, \boldsymbol{\square})$ or carrying $(\triangle, \square)$ pYV, grown at $37^{\circ} \mathrm{C}$ in magnesium/oxalate medium. In both sets of experiments, each value is the mean of two independent measurements performed with two independently grown batches of cells (coefficient of variation was less than $5 \%$ for all groups of data).

tuberculosis WS 66/89-WS 45/91-WE 23/90-WS 41/ 91, with Y. pestis KIM giving results similar to those of Y. pseudotuberculosis WS 45/91. The differences were not so conspicuous with cells grown at $26{ }^{\circ} \mathrm{C}$ and, whereas Y. pestis and all Y. pseudotuberculosis strains except WS 66/89 absorbed more polycation than when grown at $37^{\circ} \mathrm{C}, \mathrm{Y}$. enterocolitica absorbed less at $26^{\circ} \mathrm{C}$ than at $37^{\circ} \mathrm{C}$. These results were confirmed by fluorimetry with dansyl-PMB (not shown). After exposure to $\mathrm{PMB}$, electron microscopy of Y. enterocolitica WA 289 O:8 and Y. pseudotuberculosis WE 23/90 grown at 26 or $37^{\circ} \mathrm{C}$ showed OM blebbing only in the former (not shown).

The role of $\mathrm{pYV}$-encoded factors on polycation binding was examined in all pathogenic Y. enterocolitica and $Y$. 
Table 2. LPS-polycation affinities determined as the concentration of PMB and PMBN causing a $50 \%$ displacement of bound DC

Values are means $\pm \mathrm{SD}, n=4$.

\begin{tabular}{|lrrrrr|}
\hline Source of LPS & \multicolumn{2}{c}{ PMB (nM) } & & \multicolumn{2}{c|}{ PMBN (nM) } \\
\cline { 2 - 3 } \cline { 5 - 6 } & \multicolumn{1}{c}{$\mathbf{2 6}{ }^{\circ} \mathbf{C}$} & $\mathbf{3 7}{ }^{\circ} \mathbf{C}$ & & $\mathbf{2 6}{ }^{\circ} \mathrm{C}$ & $37^{\circ} \mathbf{C}$ \\
\hline Y. enterocolitica PR O: 1,6 & $940 \pm 20$ & $1300 \pm 80$ & & $900 \pm 30$ & $1560 \pm 60$ \\
Y.enterocolitica WE 245/92 O:3 & $640 \pm 10$ & $690 \pm 20$ & & $630 \pm 30$ & $630 \pm 40$ \\
Y.enterocolitica WA 289 O:8 & $800 \pm 10$ & $750 \pm 25$ & & $740 \pm 30$ & $710 \pm 35$ \\
Y.pseudotuberculosis WE 23/90 & $1220 \pm 45$ & $440 \pm 20$ & & $1190 \pm 35$ & $440 \pm 25$ \\
Y.pestis KIM & $430 \pm 35$ & $400 \pm 20$ & & $400 \pm 30$ & $420 \pm 30$ \\
\hline
\end{tabular}

pseudotuberculosis strains using dansyl-PMB. For all concentrations tested, the levels of fluorescence (proportional to the bound probe) were similar in $\mathrm{pYV}^{+}$and $\mathrm{pYV}^{-}$isogenic pairs grown in magnesium/oxalate medium at $37^{\circ} \mathrm{C}$ (Fig. $1 \mathrm{~b}$ shows representative results), thus ruling out a role of $\mathrm{pYV}$ in polycation resistance.

Functional OM damage was assessed by testing the effect of subinhibitory concentrations of polycations on OM permeability to lysozyme or novobiocin. With cells grown at $37^{\circ} \mathrm{C}$, there was an $80 \%$ decrease in turbidity (cell lysis) for pathogenic Y. enterocolitica and $Y$. pseudotuberculosis WS 66/89 but no lysis was observed for the other $Y$. pseudotuberculosis strains or for $Y$. pestis KIM. With cells grown at $26^{\circ} \mathrm{C}$, incubation with PMB-lysozyme caused decreases in turbidity of $70 \%$ for pathogenic Y. enterocolitica and Y. pseudotuberculosis WS 66/89, 55\% for the remaining Y.pseudotuberculosis strains and $30 \%$ for Y. pestis KIM. The experiments were extended to other polycations using novobiocin as probe. With no polycations, Y. pseudotuberculosis and $Y$. pestis MICs were lower than those of Y. enterocolitica (Table 1), a result in keeping with their different OM permeability to hydrophobic drugs (Bengoechea $e t$ al., 1998). Polycations increased the Y. enterocolitica novobiocin MIC 8 to 64 -fold, produced no effect on the $Y$. pestis MIC, and, depending on the polycation and strain, only increased the MIC of Y. pseudotuberculosis 2 to 4 -fold (Table 1).

\section{LPS-polycation affinities}

To test whether the observations made with live bacteria correlated with LPS affinities, LPSs were incubated with DC and the DC $50 \%$ occupancy (affinity) was assessed by displacement with PMB or PMBN (Table 2). With LPSs from bacteria grown at $37^{\circ} \mathrm{C}$, the affinity was highest for non-pathogenic Y. enterocolitica PR O:1,6, intermediate for pathogenic Y. enterocolitica WA 289 O:8 (greater than WE 245/92 O:3) and lowest for $Y$. pseudotuberculosis WE 23/90 and Y. pestis KIM $(P<$ 0.01 ; unpaired $t$-test), thus reproducing the results obtained with live cells. This parallelism was not so clear with LPSs from bacteria grown at $26^{\circ} \mathrm{C}$ because

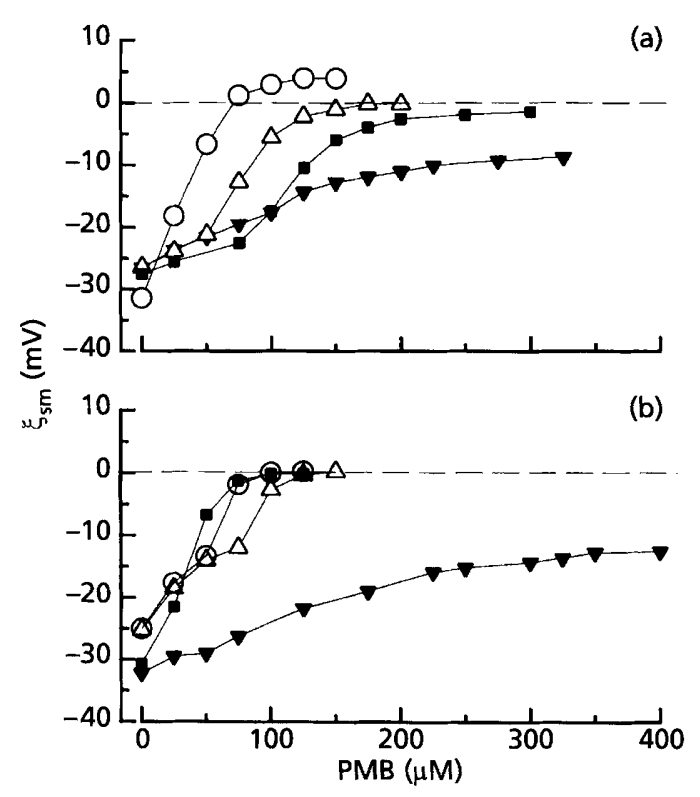

Fig. 2. Effect of PMB on the $\zeta_{s m}$ of LPS aggregates of $Y$. pestis KIM (O), Y. pseudotuberculosis WE 23/90 (D), Y. enterocolitica WA $2890: 8$ (pathogenic) $(\triangle)$ and $Y$. enterocolitica PR $0: 1,6$ (non-pathogenic) $(\boldsymbol{\nabla})$ grown at 26 (a) or $37^{\circ} \mathrm{C}(\mathrm{b})$. Each point corresponds to six measurements; the SD was so small as to be hidden by the symbols.

DC affinity decreased in the order Y.pseudotuberculosis WE 23/90-non-pathogenic Y. enterocolitica PR O:1,6pathogenic Y. enterocolitica WA 289 O:8 (greater than WE 245/92 O:3)-Y. pestis KIM. Likewise, the shifts in polycation binding by live cells grown at 26 or $37^{\circ} \mathrm{C}$ were not paralleled by clear LPS affinity shifts in pathogenic Y. enterocolitica and Y. pestis (compare Fig. 1 and Table 2).

\section{$\zeta_{\mathrm{sm}}$ of LPS aggregates and effect of polycations}

The $\zeta_{\mathrm{sm}}$ values with respect to PMB concentration are presented in Fig. 2. For the native LPS aggregates (zero $\mathrm{PMB})$ and independent of growth temperature, $\zeta_{\mathrm{sm}}$ was 
always negative with no marked differences or clear correlation with the amounts of polycation bound by live cells (Fig. 1) or LPSs (Table 2). Despite this, very different amounts of PMB were necessary to saturate $\left(\zeta_{\mathrm{sm}}=0 \mathrm{mV}\right)$ these LPS aggregates. With LPSs from cells grown at $26^{\circ} \mathrm{C}$ (Fig. 2a), saturation was achieved in the order Y. pestis KIM-Y. enterocolitica WA 289 O:8 (and WE 245/92 O:3; not shown)-Y. pseudotuberculosis WE 23/90, with no saturation for the LPS of non-pathogenic Y. enterocolitica PR O:1,6 at the highest PMB concentration tested. With LPSs from cells grown at $37^{\circ} \mathrm{C}$, the $\zeta_{\mathrm{sm}}$ vs. PMB plot of Y. pestis LPS was similar to that observed for LPSs from cells grown at $26^{\circ} \mathrm{C}$, that of $Y$. pseudotuberculosis LPS became close to that of Y. pestis LPS and a less marked shift was observed for the LPS of Y. enterocolitica WA 289 O:8 (and WE 245/92 O:3; not shown). In contrast, the LPSs of non-pathogenic $Y$. enterocolitica $\mathrm{PR} O: 1,6$ grown at $37^{\circ} \mathrm{C}$ needed larger amounts of PMB than its $26^{\circ} \mathrm{C}$ grown counterpart to reach similar $\zeta_{\mathrm{sm}}$ values. Finally, the PMB results were confirmed with PMBN, although it had a measurable reduced effect on the LPSs of pathogenic strains and species (not shown). PMBN and $\mathrm{PMB}$ had similar measurable effects on non-pathogenic Y. enterocolitica LPS.

\section{DISCUSSION}

Despite their variety of structures and origin (Nicolas \& Mor, 1995; Vaara, 1992), bactericidal cationic peptides start their action by electrostatic interaction with negatively charged groups of the surface of target cells (Nicolas \& Mor, 1995; Stivanage et al., 1989; Vaara, 1992). Thus, melittin, PMB, poly-L-lysine and poly-Lornithine mimic in part the bactericidal peptides of vertebrates and, therefore, the progressive increase in polycation resistance observed from the less invasive ( $Y$. enterocolitica) to the more intracellular ( $Y$. pestis) yersiniae strongly suggests that this property helps to overcome the increasing host defences from mucosal to phagocytic levels. This interpretation is consistent with the previous observation that whereas polycation resistance is lost at $37^{\circ} \mathrm{C}$ in non-pathogenic Y. enterocolitica, it is only reduced in pathogenic Y. enterocolitica (Bengoechea et al., 1996). Moreover, Y. pseudotuberculosis WE 23/90, WS 41/91 and WS 45/91, and $Y$. pestis KIM polycation resistance was more marked than that of pathogenic Y. enterocolitica and increased at $37^{\circ} \mathrm{C}$. Thus, the relevance of polycation resistance in the biology of yersiniae is also suggested by the fact that it is lost, kept or enhanced at the host growth temperature in accordance with the transition from non-pathogenic biogroups to the most invasive spp. It has been shown that introduction of $\mathrm{pYV}$ in nonpathogenic Y. enterocolitica does not result in virulence, despite expression of pYV-encoded factors (Heesemann et al., 1984). Since non-pathogenic Y. enterocolitica differs clearly from pathogenic yersiniae in polycation resistance (Bengoechea et al., 1996; this work), it can be speculated that this trait provides a background on which pYV acquisition leads to full virulence.

Although Y. pseudotuberculosis WS 66/89 was more resistant than pathogenic $Y$. enterocolitica, both exhibited diminished resistance at $37^{\circ} \mathrm{C}$. Compared to other Y. pseudotuberculosis strains, WS 66/89 had a higher novobiocin MIC, showing that it is closer to pathogenic $Y$. enterocolitica in terms of $\mathrm{OM}$ permeability. Thus, consistent with the transition in OM properties shown for the genus (Bengoechea et al., 1998), WS 66/89 OMs display intermediate properties. Since WS 66/89 was the only serotype III strain tested, further studies are necessary to find out whether enhanced resistance at $37^{\circ} \mathrm{C}$ is a specific property of $Y$. pseudotuberculosis or whether there is serogroup or strain variability.

In a previous study (Bengoechea et al., 1996), no differences were observed when LPS aggregates of pathogenic and non-pathogenic Y. enterocolitica were tested for polycation-induced permeability changes to hydrophobic probes. The more accurate DC measurements, however, showed affinity differences between the probe and the LPSs of pathogenic and non-pathogenic $Y$. enterocolitica, thereby explaining the observations made with viable cells of this species. Negatively charged LPS sites are located at the core and lipid A and, so far, polycation resistance in enteric bacteria has been related to O-chain steric hindrance (Peterson et al., 1986) and to a reduction of charge due to substitution of phosphates by arabinosamine and/or ethanolamine in lipid A (Guo et al., 1997; Helander et al., 1994, 1996; Nummila et al., 1995; Sidorczyk et al., 1983; Stivanage et al., 1989). Thus, it could be that there are variations in lipid A substitutions of $Y$. enterocolitica which explain the effects on live cells. However, the DC affinity measurements were not always in full agreement with the resistance of live cells for the LPSs of Y. pseudotuberculosis and Y.pestis. Although at 37 and $26^{\circ} \mathrm{C}, \mathrm{Y}$. pestis cells bound more PMB than cells of Y. pseudotuberculosis WE $23 / 90$, the DC affinity for the $26{ }^{\circ} \mathrm{C} \mathrm{Y}$. pestis LPS was much less than for the $26{ }^{\circ} \mathrm{C}$ WE $23 / 90$ LPS and similar DC affinities were observed for both $37^{\circ} \mathrm{C}$ LPSs. Also, the DC affinities were higher for the $26^{\circ} \mathrm{C}$ Y. pseudotuberculosis WE 23/90 LPS than for the $26^{\circ} \mathrm{C}$ Y. enterocolitica LPS and this also did not correlate with the lower binding shown by WE 23/90 cells. This suggests that although LPS anionic binding sites should play an important role, quantitative differences in such sites cannot account by themselves for the effects on live cells and this is consistent with the $\zeta_{s m}$ measurements. Despite the fact that neutralization of the $\zeta_{\mathrm{sm}}(0 \mathrm{mV})$ of the $26^{\circ} \mathrm{C}$ LPS aggregates required amounts of PMB and PMBN roughly correlating with the DC affinities, all LPSs had a similar $\zeta_{\mathrm{sm}}(-26$ to $-31 \mathrm{mV}$ ) in the absence of polycations. This shows that, in addition to charge, accessibility or other properties relating to the supramolecular structure of the aggregates are important in LPS-polycation interactions. It is noteworthy that reduced accessibility to internal targets caused by the O-chain (Peterson et al., 
1986) cannot account for the increased resistance of $Y$. pseudotuberculosis and Y. pestis because these bacteria have LPSs lacking long-chain polysaccharides (Bengoechea et al., 1998). Thus, peculiar core structures and interactions between LPS molecules or with other OM elements should also play a role in the resistance of live cells.

When pathogenic Y. enterocolitica is grown in the absence of $\mathrm{Ca}^{2+}$, the cells become permeable to hydrophobic agents (Bengoechea et al., 1996) and in the accompanying article (Bengoechea et al., 1998) we described that, in normal medium, Y. pseudotuberculosis and $Y$. pestis are readily permeable to such agents. In this study, Y. pseudotuberculosis and Y. pestis were found to be more resistant to polycations than Y. enterocolitica. Whether there is a structural connection in the OM between those two sets of properties is not known. The yersiniae offer the possibility of carrying out chemical and genetic studies with closely related bacteria which could help to understand the bases of those phenomena and their role in the variable environments in which they are manifested.

\section{ACKNOWLEDGEMENTS}

We are grateful to $\mathrm{H}$. Lüthje and G. von Busse for technical assistance and to R. R. Brubaker and G. Wauters for providing the Yersinia strains. Part of this work was financially supported by the Deutsche Forschungsgemeinschaft (SFB 470) and by a Universidad de Navarra PIUNA grant. Fellowship support for J.A.B. from the Eusko Jaurlaritza is also acknowledged.

\section{REFERENCES}

Bengoechea, J. A., Díaz, R. \& Moriyón, I. (1996). Outer membrane differences between pathogenic and environmental Yersinia enterocolitica biogroups probed with hydrophobic permeants and polycationic peptides. Infect Immun 64, 4891-4899.

Bengoechea, J.-A., Brandenburg, K., Seydel, U., Díaz, R. \& Moriyón, I. (1998). Yersinia pseudotuberculosis and Yersinia pestis show increased outer membrane permeability to hydrophobic agents which correlates with lipopolysaccharide acylchain fluidity. Microbiology 144, 1517-1526.

Brubaker, R. R. (1991). Factors promoting acute and chronic diseases caused by yersiniae. Clin Microbiol Rev 4, 309-324.

Cafiso, D., McLaughlin, A., McLaughlin, S. \& Wimshi, A. (1983). Measuring electrostatic potentials adjacent to membranes. Methods Enzymol 171, 342-364.

Cornelis, G., Iriarte, M. \& Sory, M.-P. (1995). Environmental control of virulence functions and signal transduction in Yersinia enterocolitica. In Signal Transduction and Bacterial Virulence, pp. 95-110. Edited by R. Rappouli, V. Scarlato \& B. Aricò. Austin, TX: R. G. Landes.

David, S. A., Balasubramanian, K. A., Mathan, V. I. \& Balaran, P. (1992). Analysis of the binding of polymyxin B to endotoxic lipid
A and core glycolipid using a fluorescent displacement probe. Biochim Biophys Acta 1165, 147-152.

Eisenhauer, P. B., Harwig, S. S. S. L. \& Lehrer, R. I. (1992). Cryptdins: antimicrobial defensins of the murine small intestine. Infect Immun 60, 3556-3565.

Groisman, E. A. (1994). How bacteria resist killing by hostdefence peptides. Trends Microbiol 2, 444449.

Guo, L., Lim, K. B., Gunn, J. S., Bainbridge, B., Darveau, R. P., Hackett, M. \& Miller, S. I. (1997). Regulation of lipid A modifications by Salmonella typhimurium virulence genes phoPphoQ. Science 276, 250-253.

Heesemann, J., Algermissen, B. \& Laufs, R. (1984). Genetically manipulated virulence of Yersinia enterocolitica. Infect Immun 46, 105-110.

Helander, I. M., Kilepeläinen, I. \& Vaara, M. (1994). Increased substitution of phosphate groups in lipopolysaccharides and lipid A of the polymyxin-resistant pmrA mutants of Salmonella typhimurium: a ${ }^{31}$ P-NMR study. Mol Microbiol 11, 481-487.

Helander, I. M., Kato, Y., Kilepeläinen, Y., Kostianen, R., Lindner, B., Nummila, K., Sugiyama, T. \& Yokochi, Y. (1996). Characterization of lipopolysaccharides of polymyxin-resistant and polymyxin-sensitive Klebsiella pneumoniae O3. Eur J Biochem 237, 272-278.

Hunter, R. J. (1981). Zeta Potential in Colloid Science. London: Academic Press.

Martínez de Tejada, G., Pizarro-Cerdá, J., Moreno, E. \& Moriyón, I. (1995). The outer membranes of Brucella spp. are resistant to bactericidal cationic peptides. Infect Immun 63, 3054-3061.

Nicolas, P. \& Mor, A. (1995). Peptides as weapons against microorganisms in the chemical defence system of vertebrates. Annu Rev Microbiol 49, 277-304.

Nummila, K., Kilepeläinen, I., Zähringer, U., Vaara, M. \& Helander, I. M. (1995). Lipopolysaccharides of polymyxin B-resistant mutants of Escherichia coli are extensively substituted by 2aminoethyl pyrophosphate and contain aminoarabinose in lipid A. Mol Microbiol 16, 271-278.

Peterson, A. A., Haug, A. \& McGroarty, E. J. (1986). Physical properties of short- and long-O-antigen containing fractions of lipopolysaccharide from Escherichia coli O111:B4. J Bacteriol $165,116-122$.

Riley, G. \& Toma, S. (1989). Detection of pathogenic Yersinia enterocolitica by using Congo red-magnesium oxalate agar medium. J Clin Microbiol 27, 213-214.

Schindler, P. R. G. \& Tauber, M. (1975). Action of polymyxin B on bacterial membranes: morphological changes in the cytoplasm and in the outer membrane of Salmonella typhimurium and Escherichia coli B. Antimicrob Agents Chemother 8, 94-104.

Selsted, M. E., Miller, S. I., Henschen, A. H. \& Oullette, A. J. (1992). Enteric defensins: antibiotic peptide components of intestinal defence. $J$ Cell Biol 118, 929-936.

Sidorczyk, Z., Zähringer, U. \& Rietschel, E. T. (1983). Chemical structure of the lipid A components of the lipopolysaccharide from a Proteus mirabilis Re mutant. Eur J Biochem 137, 15-22.

Skurnik, M. \& Toivanen, P. (1992). LcrF is the temperature regulated activator of the yadA gene of Yersinia enterocolitica and Yersinia pseudotuberculosis. J Bacteriol 174, 2047-2051.

Stivanage, P., Martin, L. E. \& Spitznagel, J. (1989). O antigen and lipid A phosphoryl groups in resistance of Salmonella typhimurium LT-2 to nonoxidative killing in human polymorphonuclear neutrophils. Infect Immun 57, 3894-3900.

Straley, S. C. \& Harmon, P. A. (1984a). Growth in mouse peritoneal 
macrophages of Yersinia pestis lacking established virulence determinants. Infect Immun 45, 649-654.

Straley, S. C. \& Harmon, P. A. (1984b). Yersinia pestis grows within phagolysosomes in mouse peritoneal macrophages. Infect Immun 45, 655-659.

Straley, S. C. \& Perry, R. (1995). Environmental modulation of gene expression and pathogenesis in Yersinia. Trends Microbiol 3, 310-317.
Vaara, M. (1992). Agents that increase the permeability of the outer membrane. Microbiol Rev 56, 395-411.

Vaara, M. \& Vaara, T. (1983). Polycations sensitize enteric bacteria to antibiotics. Antimicrob Agents Chemother 24, 107-113.

Received 3 July 1997; revised 8 December 1997; accepted 16 February 1998. 